\title{
MHY-449, a novel dihydrobenzofuro[4,5-b][1,8] naphthyridin- 6-one derivative, induces apoptotic cell death through modulation of Akt/FoxO1 and ERK signaling in PC3 human prostate cancer cells
}

\author{
SUN HWA LEE* , YONG JUNG KANG* , BOKYUNG SUNG, DONG HWAN KIM, HYUN SOOK LIM, HYE RIM KIM, \\ SEONG JIN KIM, JEONG-HYUN YOON, HYUNG RYONG MOON, HAE YOUNG CHUNG and NAM DEUK KIM \\ College of Pharmacy, Molecular Inflammation Research Center for Aging Intervention (MRCA), \\ Pusan National University, Busan 609-735, Republic of Korea
}

Received November 23, 2013; Accepted December 23, 2013

DOI: 10.3892/ijo.2014.2257

\begin{abstract}
Previously, we reported on the anticancer effect of the diastereoisomeric compound MHY-449, a novel dihydrobenzofuro[4,5-b][1,8] naphthyridin-6-one derivative, in HCT116 human colon cancer cells. In the current study, we investigated whether MHY-449 has anticancer effect in prostate cancer cells, and if so, what the molecular mechanisms are. We examined the growth inhibitory effect of MHY-449 on p53 wild-type (p53-wt) LNCaP (androgen-dependent) and p53-null PC3 (androgen-independent) prostate cancer cells. MHY-449 treatment in androgen-independent and p53-null PC3 cells resulted in inhibition of cell growth and induction of apoptosis in a concentration-dependent manner. However, MHY-449 did not show any significant effects on the growth inhibition and apoptotic cell death in androgen-dependent and p53-wt LNCaP cells. Therefore, we used PC 3 cells for further studies. The induction of apoptosis in PC 3 cells was observed by decreased viability, DNA fragmentation, cleavage of poly (ADP-ribose) polymerase, activations of caspase- $3,-8$ and -9 , and alteration in the ratio of $\mathrm{Bax} / \mathrm{Bcl}-2$ protein expression. In addition, MHY-449 induced increase of late apoptosis and sub-G1 DNA which were observed by flow cytometry analysis. Furthermore, MHY-449 reduced the phosphorylation of Akt and FoxO1 and induced the translocation of FoxO1 from cytoplasm to nucleus as shown by western blot analysis. MHY-449 treatment activated extracellular signal-regulated kinase (ERK) signaling in a concentration-dependent
\end{abstract}

Correspondence to: Dr Nam Deuk Kim, Department of Pharmacy, College of Pharmacy, Pusan National University, Busan 609-735, Republic of Korea

E-mail: nadkim@pusan.ac.kr

*Contributed equally

Key words: MHY-449, prostate cancer cells, apoptosis, Akt, FoxO1, extracellular signal-regulated kinase manner. MHY-449-induced apoptosis was partially prevented by pretreatment with the ERK inhibitor PD98059 suggesting involvement of ERK in the MHY-449-induced apoptosis. Taken together, these findings suggest that MHY-449 induces apoptosis via downregulation of the Akt/FoxO1 and activation of ERK in androgen-independent, p53-null and PTEN-negative PC3 human prostate cancer cells.

\section{Introduction}

Prostate cancer ( $\mathrm{PCa})$ is one of the most common neoplasms among aging males. As of 2011, PCa is the second most frequently diagnosed cancer and the sixth leading cause of cancer death in male worldwide (1). In 2010 it resulted in 256,000 deaths, up from 156,000 deaths in 1990 (2). PCa is a prevalent malignancy in American men, with 217,730 estimated new cases that occurred in 2010 and almost 32,050 deaths (American Cancer Society, 2010). Early stage PCa uniquely relies on androgens for proliferation, and blockade of the androgen receptor pathway almost invariably induces tumor regression. However, in later stages, PCa cells become androgen-independent and no curative therapy exists for this refractory disease $(3,4)$.

Although improved screening methods allow a diagnosis of prostate cancer at an early stage, it still remains one major cause of death in men in industrialized countries. In particular, no curative treatment is available to date upon progression to androgen-independent and metastatic disease $(5,6)$. Although advances in chemotherapy have improved patient outcome $(4,5)$, there remains a clear need for effective mechanism-based therapeutic approaches that can achieve long-term improvements in patient outcomes (7).

MHY-449, $( \pm)-\left(\mathrm{R}^{*}\right)-5$-methoxy-11-methyl-2-(( $\left.\mathrm{R}^{*}\right)-2-$ methyloxiran-2-yl)-1,2-dihydrobenzofuro[4,5-b][1,8] naphthyridin- $6(11 \mathrm{H})$-one, was designed and synthesized on the basis of the chemical structure of psorospermin with a xanthone template and acronycine derivatives with an acridone template and its cytotoxicity was evaluated against five human cancer cell lines, such as prostate cancer cell lines 
(LNCaP, DU145 and PC3) and breast cancer cell lines (MCF-7/ADR and MCF-7) (8). MHY-449 has shown cytotoxicity against human prostate and breast cancer cells and induction of $\mathrm{G} 2 / \mathrm{M}$ phase arrest of the cell cycle in MCF-7/ADR cells (8). Moreover, MHY-449 was shown to inhibit effectively human colon cancer cell growth by inducing G2/M phase cell cycle arrest and apoptosis in HCT116 human colon cancer cells (9). However, the underlying molecular mechanisms of the cytotoxic effect of MHY-449 in PCa cells were not fully elucidated. Therefore, the current study was designed to investigate the cytotoxic effect of MHY-449 on p53 wild-type (p53-wt) LNCaP cells and p53 null type (p53-null) PC 3 cells and its molecular mechanisms of action.

\section{Materials and methods}

Chemicals. The simplified code name and structure of MHY-449 [( $( \pm)-\left(\mathrm{R}^{*}\right)-5$-methoxy-11-methyl-2-(( $\left.\mathrm{R}^{*}\right)$-2-methyloxiran-2-yl)1,2-dihydrobenzofuro[4,5-b][1,8]naphthyridin-6(11H)-one] used in this study is shown in Fig. 1. Detailed method for the design and synthesis of this compound is described elsewhere (9). The compound was dissolved in dimethylsulfoxide (DMSO) and stored at $-20^{\circ} \mathrm{C}$ before the experiments and dilutions were made in culture medium. The maximal concentration of DMSO did not exceed $0.1 \%(\mathrm{v} / \mathrm{v})$ in the treatment range, where there was no influence on the cell growth. Antibodies specific for Bax, Bcl-2, caspase-3, -8, poly (ADP-ribose) polymerases (PARP), Akt, p-Akt, Forkhead-Box Class O (FoxO) 1, and p-FoxO1 were obtained from Santa Cruz Biotechnology (Santa Cruz, CA, USA). Antibodies against for extracellular signal-regulated kinases (ERK), phospho(p)-ERK, c-Jun N-terminal kinases (JNK), p-JNK, p38 mitogen-activated protein kinases (MAPK) and p-p38 MAPK were purchased from Cell Signaling (Beverly, MA, USA). PD98059 was from Santa Cruz Biotechnology.

Cell culture and cell viability assay. The human prostate cancer cell lines p53-null PC3 and p53-wt LNCaP cells were cultured in RPMI-1640 (HyClone, Logan, UT, USA) supplemented with $10 \%$ fetal bovine serum (FBS, HyClone), $2 \mathrm{mM}$ glutamine (Sigma-Aldrich Co., St. Louis, MO, USA), $100 \mathrm{U} / \mathrm{ml}$ penicillin (HyClone), and $100 \mu \mathrm{g} / \mathrm{ml}$ streptomycin (HyClone) at $37^{\circ} \mathrm{C}$ in a humidified $5 \% \mathrm{CO}_{2}$. Cell viability was determined by MTT assay. For the MTT assay, PC3 and LNCaP cells were seeded in a 24-well culture plate, cultured for $24 \mathrm{~h}$ in the growth media, and then treated with or without various reagents for the indicated concentrations. The cells were incubated with $0.5 \mathrm{mg} / \mathrm{ml}$ MTT [3-(4,5-dimethylthiazol2-yl)-2,5-diphenyltetrazolium bromide] (Sigma-Aldrich) at $37^{\circ} \mathrm{C}$ for $2 \mathrm{~h}$. The formazan granules generated by the live cells were dissolved in DMSO, and the absorbance at $540 \mathrm{~nm}$ was monitored by using a multi-well reader.

Nuclear staining with Hoechst 33342. Cells were washed with PBS and fixed with $3.7 \%$ paraformaldehyde (Sigma-Aldrich) in PBS for $10 \mathrm{~min}$ at room temperature. Fixed cells were washed with PBS, and stained with $4 \mu \mathrm{g} / \mathrm{ml}$ Hoechst 33342 (Invitrogen, Eugene, OR, USA) for $20 \mathrm{~min}$ at room temperature. The cells were washed two more times with PBS and analyzed via a fluorescent microscope.

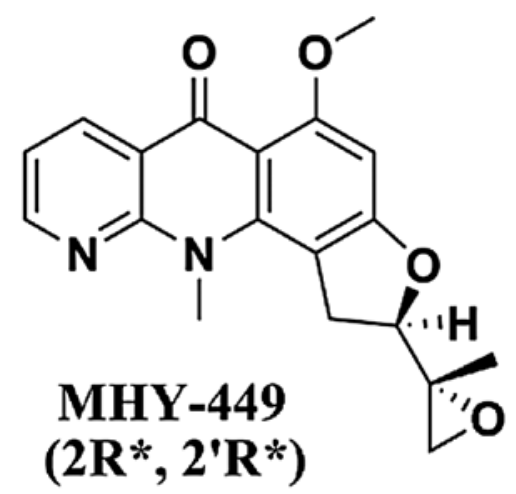

Figure 1.Chemical structure of MHY-449 [( \pm )-( $\left(\mathrm{R}^{*}\right)-5$-methoxy-11-methyl-2-((R*)-2methyloxiran-2-yl)-1,2-dihydrobenzofuro[4,5-b][1,8]naphthyridin-6(11H)-one].

Assessment of DNA fragmentation. Cells were lysed in a buffer, containing $5 \mathrm{mM}$ Tris- $\mathrm{HCl}(\mathrm{pH} 7.5), 5 \mathrm{mM}$ EDTA, and $0.5 \%$ Triton X-100, for $30 \mathrm{~min}$ on ice. Lysates were vortexed and cleared by centrifugation at $27,000 \mathrm{xg}$ for $20 \mathrm{~min}$. Fragmented DNA in the supernatant was treated with RNase, followed by proteinase $\mathrm{K}$ digestion, phenol/chloroform/isoamyl alcohol mixture (25:24:1, v/v/v) extraction and isopropanol precipitation. DNA was separated through a $1.6 \%$ agarose gel, and stained with $0.1 \mu \mathrm{g} / \mathrm{ml}$ ethidium bromide (EtBr, Fluka), and then visualized by UV source.

Flow cytometric analysis. The DNA content was measured following the staining of the cells with propidium iodide (PI, Sigma-Aldrich). The cells were treated under the appropriate conditions for $24 \mathrm{~h}$, subsequently trypsinized, washed once in cold PBS, and then fixed in $70 \%$ ethanol at $-20^{\circ} \mathrm{C}$ overnight. The fixed cells were pelleted and stained in cold PI solution $(50 \mu \mathrm{g} / \mathrm{ml}$ in PBS) at room temperature for $30 \mathrm{~min}$ in the dark. The stained cells were analyzed by flow cytometry (FC500, Beckman Coulter, Istanbul, Turkey).

Assay of caspase activity. The cells were harvested and washed with cold PBS. Total cells were lysed with the lysis buffer [40 mM Tris (pH 8.0), $120 \mathrm{mM}, \mathrm{NaCl}, 0.5 \%$ NP-40, $0.1 \mathrm{mM}$ sodium orthovanadate, $2 \mu \mathrm{g} / \mathrm{ml}$ aprotinin, $2 \mu \mathrm{g} / \mathrm{ml}$ leupeptin and $100 \mu \mathrm{g} / \mathrm{ml}$ phenymethylsulfonyl fluoride (PMSF)] at $4^{\circ} \mathrm{C}$ for $30 \mathrm{~min}$. The lysed cells were centrifuged at $10,000 \mathrm{x} \mathrm{g}$ for $2 \mathrm{~min}$, and $100 \mu \mathrm{g}$ of protein was incubated with $100 \mu \mathrm{l}$ of reaction buffer and $10 \mu 1$ of colorimetric tetrapeptides, Z-DEVDpNA for caspase-3, Z-IETD-pNA for caspase-8, and Ac-LEHD-pNA for caspase-9, respectively. The reaction mixture was incubated at $37^{\circ} \mathrm{C}$ for $30 \mathrm{~min}$ and liberated p-nitroaniline (pNA) was measured at $405 \mathrm{~nm}$ using a multi-well reader.

Annexin V staining. Annexin V-FITC is used to quantitatively determine the percentage of cells within a population that are actively undergoing apoptosis. The cells were treated under the appropriate conditions for $24 \mathrm{~h}$, subsequently harvested, trypsinized, washed once in cold PBS, suspended the cells in $1 \mathrm{X}$ binding buffer (Becton-Dickinson, Annexin V-FITC Apoptosis Detection Kit). The counted cells were stained in PI and Annexin V-FITC solution (Becton-Dickinson, 
Annexin V-FITC Apoptosis Detection Kit) at room temperature for $15 \mathrm{~min}$ in the dark. The stained cells were analyzed by flow cytometry within $1 \mathrm{~h}$.

Gel electrophoresis and western blot analysis. The cells were treated under the appropriate conditions, harvested and washed with cold PBS. Total cells were lysed in lysis buffer [40 mM Tris ( $\mathrm{pH} 8.0), 120 \mathrm{mM} \mathrm{NaCl}, 0.5 \%$ NP-40, $0.1 \mathrm{mM}$ sodium orthovanadate, $2 \mu \mathrm{g} / \mathrm{ml}$ aprotinin, $2 \mu \mathrm{g} / \mathrm{ml}$ leupeptin and $100 \mu \mathrm{g} / \mathrm{ml}$ phenymethylsulfonyl fluoride (PMSF)]. Protein extracts were denatured by boiling at $100^{\circ} \mathrm{C}$ for $5 \mathrm{~min}$ in sample buffer (0.5 M Tris-HCl, pH 6.8, 4\% SDS, 20\% glycerol, $0.1 \%$ bromophenol blue, $10 \% \beta$-mercaptoethanol). Equal amount of the total proteins were subjected to 6-15\% SDS-PAGE and transferred to PVDF membrane. The membranes were blocked with $5 \%$ non-fat dry milk in Tris-buffered saline with Tween-20 buffer (TBS-T; $20 \mathrm{mM}$ Tris, $100 \mathrm{mM} \mathrm{NaCl}, \mathrm{pH} 7.5$ and $0.1 \%$ Tween-20) for $1 \mathrm{~h}$ at room temperature. Then, the membranes were incubated overnight at $4{ }^{\circ} \mathrm{C}$ with the primary antibodies. The membranes were washed with TBS-T buffer and incubated for $1 \mathrm{~h}$ with horseradish peroxidase-conjugated anti-rabbit or anti-mouse immunoglobin (Santa Cruz Biotechnology). The membranes were washed again with TBS-T buffer. Antigen-antibody complexes were detected by the enhanced chemiluminescence (ECL) detection system (Amersham Biosciences Co., Little Chalfont, UK).

Statistical analysis. Results were expressed as the mean \pm SD of three separate experiments and analyzed by Student's t-test. Means were considered significantly different at ${ }^{*} \mathrm{p}<0.05$ or ${ }^{* *} \mathrm{p}<0.01$.

\section{Results}

MHY-449 has stronger anti-proliferation effect on PC3 cells than LNCaP cells. To evaluate the effects of MHY-449 on cell growth of a human prostate cancer cell line, the MTT assay was performed. As shown in Fig. 2, treatment with MHY-449 showed concentration- and time-dependent cytotoxicity on p53-null PC3 and p53-wt LNCaP cells. However, p53-null PC3 cells were more sensitive to MHY-449 than p53-wt LNCaP cells. The $\mathrm{IC}_{50}$ value of MHY-449 was approximately 0.75 and $0.5 \mu \mathrm{M}$ at 24 and $48 \mathrm{~h}$ in PC3 cells, respectively, whereas the $\mathrm{IC}_{50}$ value of MHY-449 was approximately $1 \mu \mathrm{M}$ at $48 \mathrm{~h}$ in p53-wt LNCaP cells.

MHY-449 induces apoptosis in PC3 cells. To investigate whether the growth inhibitory effects of MHY-449 were due to the induction of apoptosis in LNCaP and PC3 cells, microphotographs were observed. LNCaP and PC3 cells treated with MHY-449 showed apparently distinct morphological changes compared with control (Fig. 3A). Although p53-wt LNCaP cells did not show significant decrease of cell numbers and morphological changes with MHY-449 treatment (Fig. 3Aa-d), p53-null PC3 cells showed prominent decrease of cell numbers and morphological changes concentrationdependently (Fig. 3Ae-h), and they were rounded and more dispersed with aggregation. Further morphological changes of cellular structures were assessed with Hoechst 33342 staining.

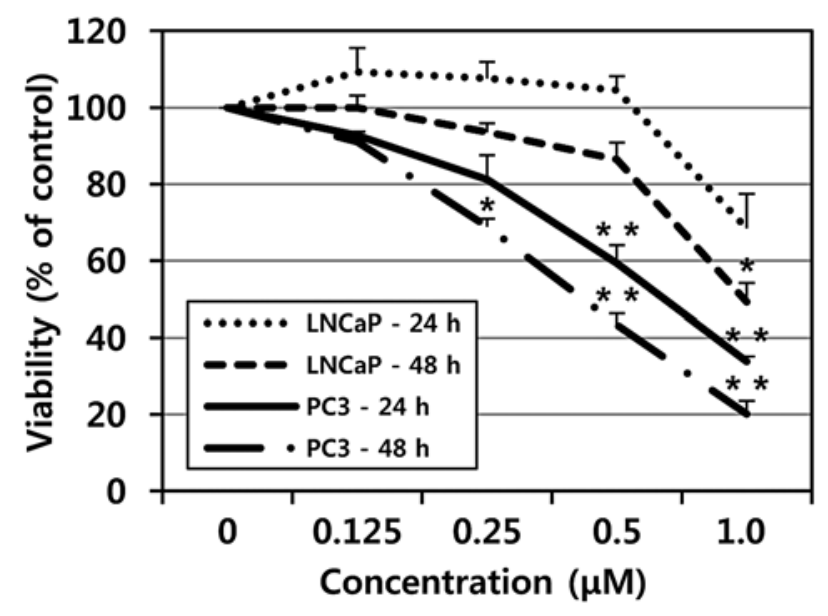

Figure 2. Concentration- and time-dependent effects of MHY-449 on the viability of LNCaP and PC3 cells. To study anti-proliferative effects of MHY-449, cells were treated with the indicated concentrations of MHY-449 for 24 and $48 \mathrm{~h}$. Proliferation was measured by using MTT assay. Results are expressed as mean \pm SD $(n=6)$ and as a percentage of vehicle-treated control The significance was determined by Student's t-test. ${ }^{*} \mathrm{p}<0.05$ and ${ }^{* *} \mathrm{p}<0.01$ compared between vehicle-treated control cells

As shown in Fig. 3Be-h, nuclei with chromatin condensation and formation of apoptotic bodies, which are characteristics of apoptosis, were seen in p53-null PC3 cells cultured with MHY-449 concentration-dependently, whereas the control cells maintained the nuclear structure intact. However, p53-wt LNCaP cells did not show any morphological changes of the nuclei after MHY-449 treatment. We also analyzed whether DNA fragmentation, another hallmark of apoptosis, was induced by MHY-449 treatment on LNCaP and PC3 cells. Following agarose gel electrophoresis of LNCaP and PC3 cells treated with MHY-449 for $24 \mathrm{~h}$, a typical ladder pattern of internucleosomal fragmentation was observed in a concentration-dependent manner in p53-null PC3 cells, but not in p53-wt LNCaP cells (Fig. 4A). Polypeptide degradation, including poly(ADP-ribose) polymerase (PARP), was examined to see the possible involvement of apoptosis-associated protease during the growth inhibition of PCa cells. PARP cleavage was evident by the appearance of the p85 PARP cleavage fragment and clearly observed in the $0.25,0.5$ and $1.0 \mu \mathrm{M}$ of MHY-449 treatment in p53-null PC3 cells (Fig. 4B, right panel). However, p53-wt LNCaP cells did not show any PARP cleavage after MHY-449 treatment (Fig. 4B, left panel). These results suggest that MHY-449 induced apoptotic cell death in p53-null PC3, not in p53-wt LNCaP cells. Therefore, p53-null PC3 cells were used for further studies.

To confirm apoptosis of MHY-449 in p53-null PC3 cells, flow cytometry analysis was performed. As shown in Fig. 5A, increases of early apoptosis (lower right quadrant) and late apoptosis/death (upper right quadrant) were clearly observed concentration-dependently. Moreover, the percentages of apoptotic cells, sub-G1 fraction, were significantly increased in p53-null PC3 cells treated with MHY-449 in a concentration-dependent manner (Fig. 5B).

MHY-449 upregulates the expression levels of apoptosis-related proteins and increases caspase activities in 

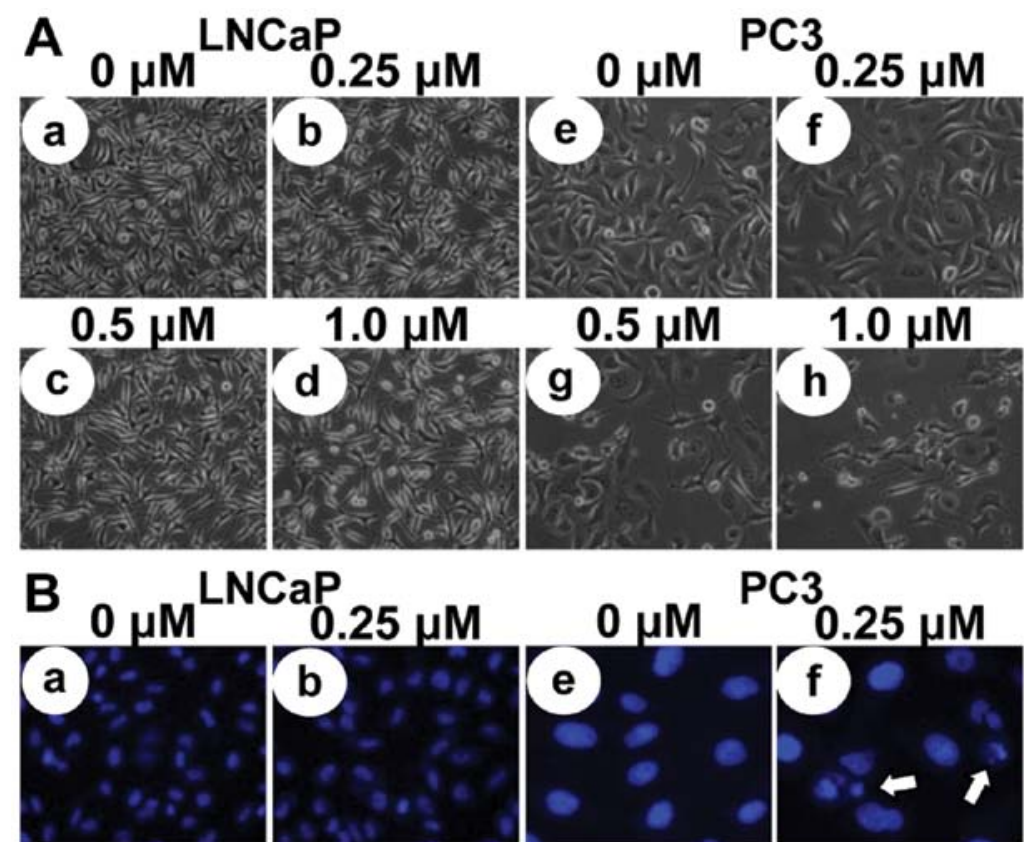

$\mathrm{NCaP}$
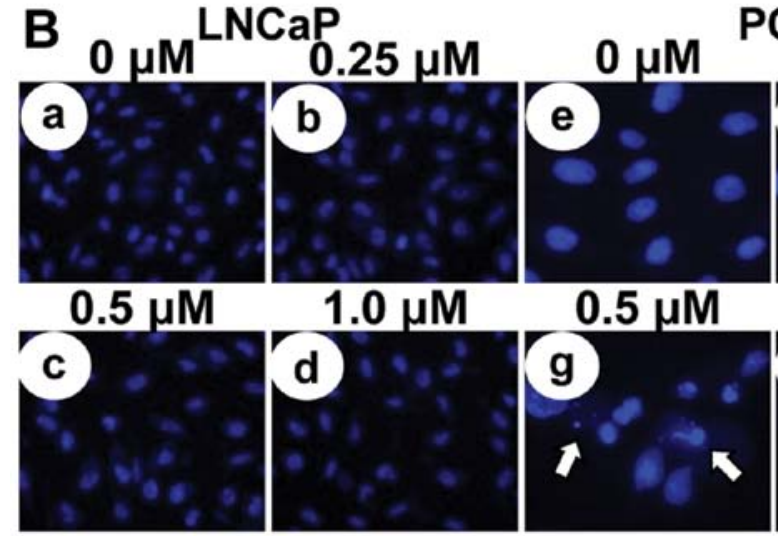

$\mathrm{PC} 3$
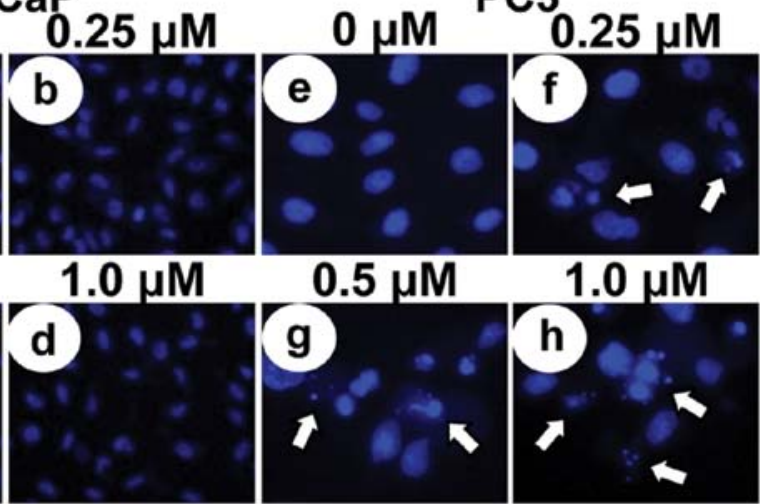

Figure 3. Morphological changes in LNCaP and PC3 cells treated with MHY-449. (A) LNCaP (a-d) and PC3 (e-h) cells were treated for $24 \mathrm{~h}$ with the indicated concentrations of MHY-449 and morphological changes were observed by phase contrast microscopy at x400 magnification. (B) Stained nuclei of LNCaP (a-d) and PC3 (e-h) cells with fluorescent DNA-binding dye, Hoechst 33342, were then photographed with a fluorescence microscope using a blue filter at x400 magnification. Apoptotic cells (arrow).

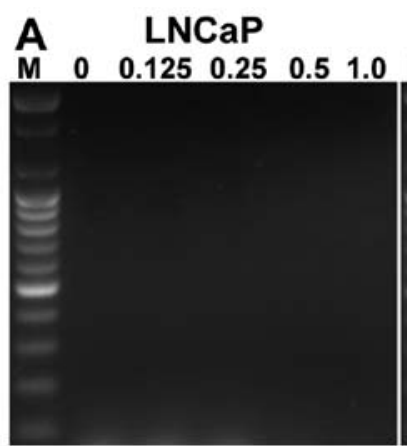

B LNCaP

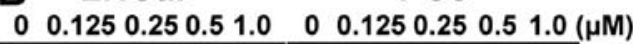

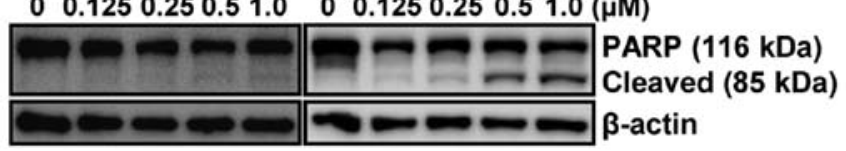

Figure 4. Effect of MHY-449 on apoptosis in LNCaP and PC3 cells. (A) To analyze fragmentation of genomic DNA, $\mathrm{LNCaP}$ and $\mathrm{PC} 3$ cells were treated with indicated concentrations of MHY-449 for $24 \mathrm{~h}$. DNA was extracted and analyzed by $1.6 \%$ agarose gel electrophoresis in the presence of EtBr. A representative result is shown from three independent experiments. $\mathrm{M}$, marker. (B) $\mathrm{LNCaP}$ and PC 3 cells were treated with indicated concentrations of MHY-449 for $24 \mathrm{~h}$, collected, lysed and then cellular proteins were separated and immunoblotted. The membranes were probed with PARP (116 kDa). Protein was visualized using the ECL detection system. Representative results from three independent experiments are shown. Actin was used as a loading control.
PC3 cells. To determine whether the expression levels of apoptosis-related proteins were modulated by MHY-449 in PC3 cells, western blot analysis was performed. The expression level of Bcl-2 protein was markedly downregulated, while Bax was upregulated in a concentration-dependent manner (Fig. 6A). The ratio between Bcl-2 and Bax has been suggested as a primary event in determining the susceptibility to apoptosis (10). These data suggest that MHY-449 induces apoptosis by the alteration in expression ratio of $\mathrm{Bax} / \mathrm{Bcl}-2$ protein. In an attempt to further characterize the mechanisms of apoptosis induced by MHY-449, the activities of caspase $-3,-8$ and -9 were determined by colorimetric assay. The activities of caspase- 3 and -8 were increased with the treatment of MHY-449 concentration-dependently and there was little change in caspase-9 activity (Fig. 6B). Therefore, these results suggested that MHY-449 induce caspase-dependent apoptosis in p53-null PC3 cells.

MHY-449-induced apoptosis is associated with Akt/FoxO pathway. To clarify the molecular mechanism of apoptotic cell death in p53-null PC3 cells, we hypothesized that MHY-449-induced apoptosis in p53-null PC3 cells was due to inhibition of $\mathrm{Akt} / \mathrm{FoxO}$ pathway. To test our hypothesis, the level of Akt was first examined in whole lysate by western blot analysis. p53-null PC3 cells are also PTEN-negative via homozygous deletion (11). Therefore, deletion of PTEN in 

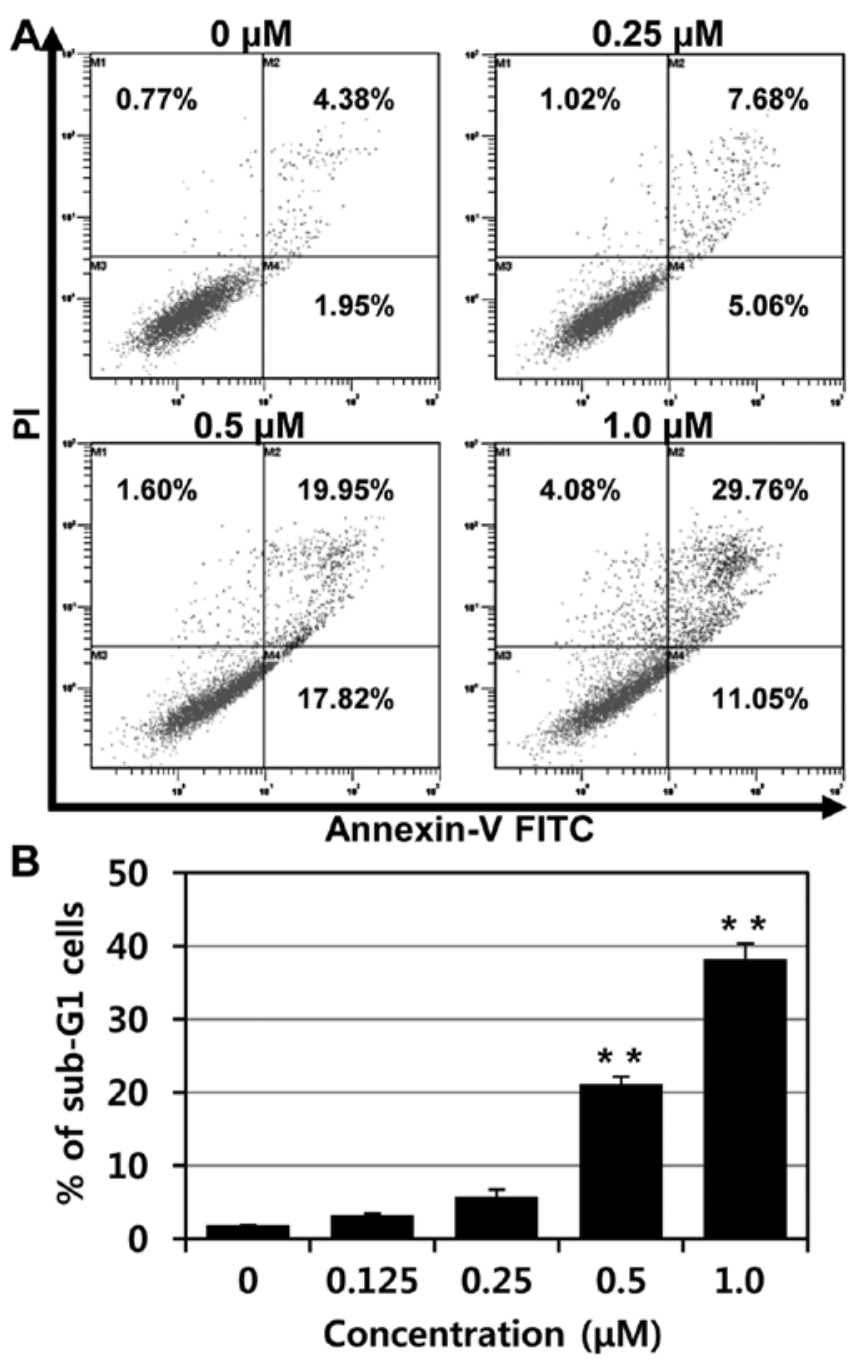

Figure 5. Induction of apoptosis in PC3 cells by MHY-449. (A) To investigate the effect of MHY-449 on cell death, PC3 cells were treated for $24 \mathrm{~h}$ with the indicated concentrations of MHY-449. Annexin V binding and PI uptake in non-permeabilized cells were analyzed by flow cytometry. (B) PC3 cells at $60-70 \%$ confluence were treated with the indicated concentrations of MHY-449 for $24 \mathrm{~h}$. The presence of cells with sub-G1 DNA content following treatment with MHY-449 was evaluated using flow cytometry in order to quantify the onset of apoptosis. The significance was determined by Student's t-test. ${ }^{* *} \mathrm{p}<0.01$ vs. vehicle-treated control cells.

PC 3 cells results in increased levels of phosphatidyl-inositol 3,4,5 triphosphate which increases activated Akt (12). As shown in Fig. 7A, phosphorylation level of Akt (p-Akt) was highly increased in vehicle-treated PC3 cells. However, p-Akt, not Akt, was drastically suppressed by MHY-449 treatment in a concentration-dependent manner. Next, we investigated the downstream molecules of Akt pathway such as FoxO1, which is known to be critical in carcinogenesis. Our results showed that phosphorylated level, but not protein level, of FoxO1 was also decreased in PC3 cells treated with MHY-449. This result clearly indicates that the reduced phosphorylated level of FoxO1 was not due to the alteration of protein expression of FoxO1 by MHY-449 treatment (Fig. 7A). Phosphorylation of FoxO1 by Akt leads to interaction with chaperone protein, such as 14-3-3, which serve as escort proteins for FoxO1 to move out of the nucleus
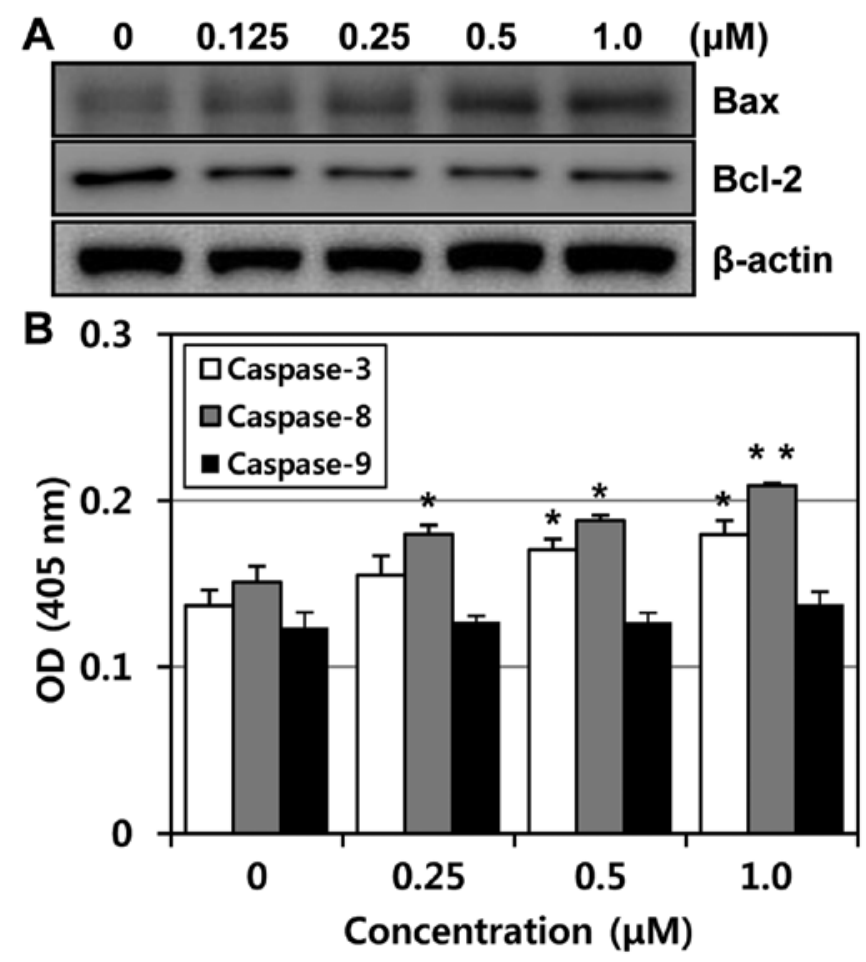

Figure 6. Effects of MHY-449 on the protein expressions of Bax, Bcl-2 and caspases in PC3 cells. (A) PC3 cells were treated with variable concentrations of MHY-449 for $24 \mathrm{~h}$ and total cell lysates were prepared and immunoblotted for Bax and Bcl-2. Representative results from three independent experiments are shown. Actin was used as a loading control. (B) To detect caspase activities, cell lysates from cells treated with MHY- 449 for $24 \mathrm{~h}$ were assayed for in vitro caspase-3, -8 and -9 activity using Z-DEVD-pNA, Z-IETD-pNA, and Ac-LEHD-pNA, respectively, as substrates at $37^{\circ} \mathrm{C}$ for $2 \mathrm{~h}$. The released fluorescent products were measured. The data represent the mean $\pm \mathrm{SD}$ values of three independent experiments. The significance was determined by Student's t-test. ${ }^{*} \mathrm{p}<0.05$ and ${ }^{* *} \mathrm{p}<0.01$ vs. vehicle-treated control cells.

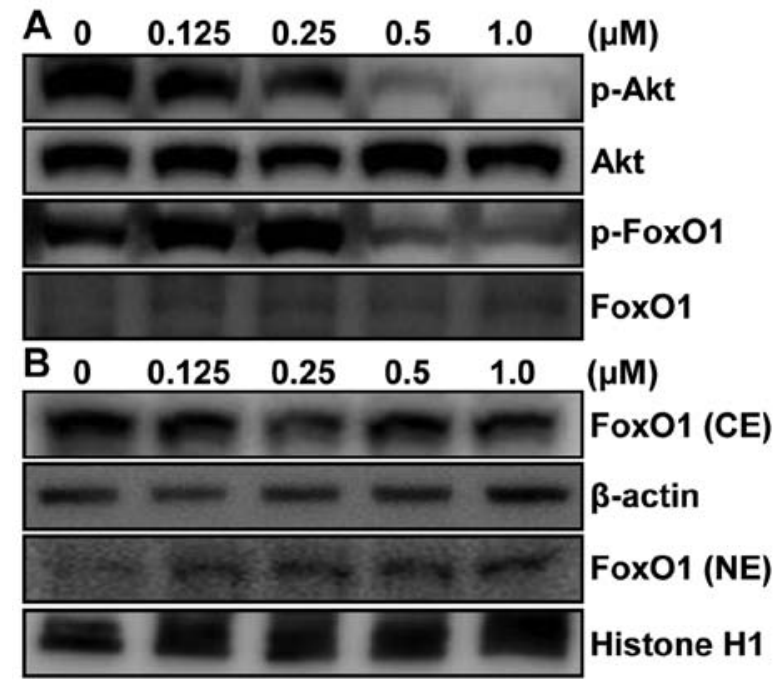

Figure 7. Effect of MHY-449 on Akt/FoxO1 pathway in PC3 cells. (A) PC3 cells were treated with various concentrations of MHY-449 for $24 \mathrm{~h}$ and total cell lysates were prepared and immunoblotted for p-Akt (Ser-473), Akt, p-FoxO1 (Ser-256) and FoxO1. Representative results from three independent experiments are shown. Actin was used as a loading control. (B) To track the subcellular localization of FoxO1 protein, nuclear extracts (NE) and cytosolic extracts (CE) from control and MHY-449-treated PC3 cells were probed for FoxO1 by immunoblotting. Representative results from three independent experiments are shown. Actin or histone H1 was used as a loading control. 

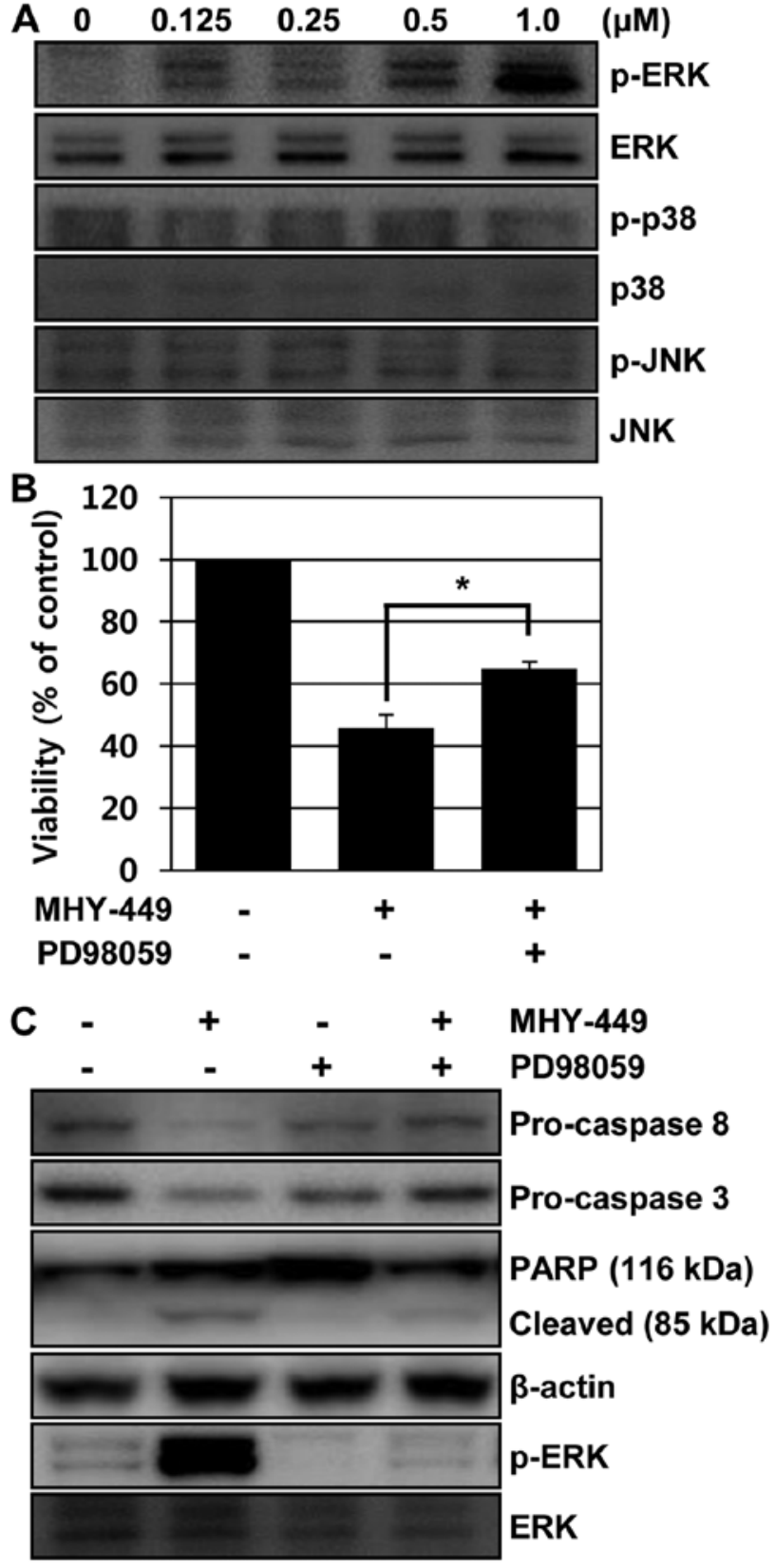

Figure 8. Role of MAPKs on MHY-449-induced apoptosis in PC3 cells. (A) PC3 cells were treated with various concentrations of MHY-449 for $24 \mathrm{~h}$ and total cell lysates were prepared and immunoblotted for p-ERK, ERK, $\mathrm{p}-\mathrm{p} 38, \mathrm{p} 38, \mathrm{p}-\mathrm{JNK}$ and JNK. Representative results from three independent experiments are shown. (B) PC3 cells were treated with $1.0 \mu \mathrm{M}$ MHY-449 for $24 \mathrm{~h}$ after pretreatment of $50 \mu \mathrm{M}$ PD98059 for $30 \mathrm{~min}$. The degree of cytotoxicity was determined by MTT assay. The data represent the mean \pm SD values of three independent experiments. The significance was determined by Student's t-test. "p<0.05 vs. MHY-449-treated cells. (C) PC3 cells were treated with or without $1.0 \mu \mathrm{M}$ MHY-449 for $24 \mathrm{~h}$ after pretreatment with or without $50 \mu \mathrm{M}$ PD98059 for $30 \mathrm{~min}$. Total cell lysates were prepared and immunoblotted for pro-caspase-8, pro-caspase-3, PARP, p-ERK and ERK. Representative results from three independent experiments are shown. Actin was used as a loading control.

(13) leading to transcriptional downregulation of several target proteins, such as Bim, p21WAF1/CIP1, and p27KIP1 (14). Thus, we assessed whether MHY-449 affects nuclear localization of FoxO1 by immunoblot analysis of nuclear and cytosolic fractions with FoxO1 antibody. Our results showed that FoxO1 protein level steadily increased in nuclear fraction and decreased in cytosolic fraction of MHY-449-treated p53-null and PTEN-negative PC3 cells (Fig. 7B).

MHY-449 induces ERK phosphorylation. To explore other intracellular signaling pathways that might be involved in MHY-449-induced apoptosis, we monitored activation of mitogen-activated protein kinases (MAPK), such as ERK, p38 MAPK and JNK by western blot analysis with phospho-specific antibodies. MHY-449 treatment of PC3 cells resulted in activation of ERK, but not in p38 MAPK and JNK, in a concentration-dependent manner (Fig. 8A). To determine whether MHY-449-induced ERK activation was required for cell toxicity, PC3 cells pretreated with PD98059, an ERK inhibitor, was subsequently exposed to MHY-449 for $24 \mathrm{~h}$, and then cell death was measured by MTT assay. Pretreatment with the ERK inhibitor protected against MHY-449-induced cytotoxicity (Fig. 8B). Similarly, pretreatment of ERK inhibitor abolished MHY-449-induced downregulation of pro-caspase- 8 and -3 and PARP cleavage (Fig. 8C). These results suggest that cell death by MHY-449 treatment requires at least activation of the ERK pathway.

\section{Discussion}

The striking new findings reported here show that two PCa cell lines with different growth dependencies and p53 and/or PTEN status reacted totally differently to the toxic effects of MHY-449. As compared to androgen-independent, p53-null and PTEN-negative PC3 cells, androgen-dependent, p53-wt and mutated PTEN (frame-shift mutation) LNCaP cells (15) were less sensitive to MHY-449 and did not show any evidence of apoptotic cell death. However, MHY-449 killed PC3 cells primarily by an apoptotic mechanism through inhibition of Akt/FoxO1 pathway and activation of ERK pathway.

FoxO factors are dysregulated in several tumor types including breast cancer (16), prostate cancer (17), glioblastoma (18), rhabdomyosarcoma (19) and leukemia (20). There are four human FoxO genes, FoxO1, 3, 4 and 6 (21). Phosphorylation of FoxOs by Akt inhibits transcriptional functions of FoxOs and contributes to cell survival, growth and proliferation $(22,23)$. The FoxO signaling is regulated by their interactions with other intracellular proteins as well as their post-translational modifications such as phosphorylation $(24,25)$.

FoxOs can induce apoptosis not only by stimulating expression of death receptor ligands, such as Fas ligand and tumor necrosis factor-related apoptosis-inducing ligand (TRAIL) but also by inducing expression of multiple pro-apoptotic members of the Bcl-2 family of mitochondria-targeting proteins. FoxOs can also promote cell cycle arrest via upregulation of the cell cycle inhibitor p27KIP1 which can induce G1 arrest or GADD45 which can cause G2 arrest $(13,26)$. In PCa, FoxO1 and the androgen receptor form a complex, which blocks the interaction between FoxO1 and its DNA response element and consequently interfering with its ability to induce apoptosis and cell cycle arrest of the PCa cells (27). Overexpression of FoxO1 and FoxO3 in $\mathrm{PCa}$ cells induces apoptosis and upregulation of TRAIL expression (17). Our results showed that the protein level of 
FoxO1 steadily increased in nuclear fraction and decreased in cytosolic fraction of MHY-449-treated PC3 cells (Fig. 7B) and consequently induced apoptotic cell death.

The MAPK pathway exists in all eukaryotes, and controls such fundamental cellular processes as proliferation, differentiation, survival and apoptosis. Mammalian MAPK can be divided into three groups based on their structure and function: ERKs, p38 MAPK and JNKs. Recent research suggests that phosphorylation of MAPKs plays an important role in the processes of apoptosis (28). MAPKs are activated by many stimuli and one of their major functions is to connect cell surface receptors to transcription factors in the nucleus, which consequently triggers long-term cellular responses (29). Depending upon the stimulus and cell type, ERK signaling pathway can transmit signals, which result in the prevention or induction of apoptosis or cell cycle progression (30). MHY-449 was shown to activate the ERK, but not p38 MAPK and JNK, and the ERK specific inhibitor PD98059 inhibited MHY-449-induced cell death and apoptosis. Therefore, it appears that MHY-449-induced apoptosis via ERK/caspase-3-dependent signaling pathway in PC3 cells.

In summary, MHY-449 suppressed growth and proliferation of androgen-independent, p53-null and PTEN-negative PC3 cells in a concentration-dependent manner by causing induction of apoptosis. Taken together, these results suggest that the novel compound MHY-449 might be used to develop adjunct treatments for a certain type of prostate cancer.

\section{Acknowledgements}

This study was supported by the National Research Foundation of Korea (NRF) grant funded by the Korea government (MSIP) (no. 2009-0083538). We thank Aging Tissue Bank for providing research information.

\section{References}

1. Jemal A, Bray F, Center MM, Ferlay J, Ward E and Forman D: Global cancer statistics. CA Cancer J Clin 61: 69-90, 2011.

2. Lozano R, Naghavi M, Foreman K, et al: Global and regional mortality from 235 causes of death for 20 age groups in 1990 and 2010: a systematic analysis for the Global Burden of Disease Study 2010. Lancet 380: 2095-2128, 2012.

3. Gelmann EP: Molecular biology of the androgen receptor. J Clin Oncol 20: 3001-3015, 2002.

4. Berry WR: The evolving role of chemotherapy in androgen-independent (hormone-refractory) prostate cancer. Urology 65: 2-7, 2005.

5. Pienta KJ and Smith DC: Advances in prostate cancer chemotherapy: a new era begins. CA Cancer J Clin 55: 300-325, 2005

6. Petrylak DP: New paradigms for advanced prostate cancer. Rev Urol 9 (Suppl 2): S3-S12, 2007.

7. LoPiccolo J, Blumenthal GM, Bernstein WB and Dennis PA: Targeting the PI3K/Akt/mTOR pathway: effective combinations and clinical considerations. Drug Resist Updat 11: 32-50, 2008.

8. Kang JA, Yang Z, Lee JY, et al: Design, synthesis and anticancer activity of novel dihydrobenzofuro $[4,5-b][1,8]$ naphthyridin6-one derivatives. Bioorg Med Chem Lett 21: 5730-5734, 2011.

9. Hwang HJ, Kang YJ, Hossain MA, et al: Novel dihydrobenzofuro[4,5-b][1,8]naphthyridin-6-one derivative, MHY-449, induces apoptosis and cell cycle arrest in HCT116 human colon cancer cells. Int J Oncol 41: 2057-2064, 2012.
10. Harris $\mathrm{MH}$ and Thompson $\mathrm{CB}$ : The role of the Bcl-2 family in the regulation of outer mitochondrial membrane permeability. Cell Death Differ 7: 1182-1191, 2000.

11. Vlietstra RJ, van Alewijk DC, Hermans KG, van Steenbrugge GJ and Trapman J: Frequent inactivation of PTEN in prostate cancer cell lines and xenografts. Cancer Res 58: 2720-2723, 1998.

12. McCubrey JA, Steelman LS, Chappell WH, et al: Roles of the Raf/MEK/ERK pathway in cell growth, malignant transformation and drug resistance. Biochim Biophys Acta 1773: 1263-1284, 2007.

13. Greer EL and Brunet A: FOXO transcription factors at the interface between longevity and tumor suppression. Oncogene 24: 7410-7425, 2005.

14. Essafi A, Fernandez de Mattos S, Hassen YA, et al: Direct transcriptional regulation of $\mathrm{Bim}$ by FoxO3a mediates STI571-induced apoptosis in Bcr-Abl-expressing cells. Oncogene 24: 2317-2329, 2005.

15. Li J, Yen C, Liaw D, et al: PTEN, a putative protein tyrosine phosphatase gene mutated in human brain, breast, and prostate cancer. Science 275: 1943-1947, 1997.

16. Hu MC, Lee DF, Xia W, et al: IkappaB kinase promotes tumorigenesis through inhibition of forkhead FOXO3a. Cell 117: 225-237, 2004

17. Modur V, Nagarajan R, Evers BM and Milbrandt J: FOXO proteins regulate tumor necrosis factor-related apoptosis inducing ligand expression. Implications for PTEN mutation in prostate cancer. J Biol Chem 277: 47928-47937, 2002.

18. Seoane J, Le HV, Shen L, Anderson SA and Massague J: Integration of Smad and forkhead pathways in the control of neuroepithelial and glioblastoma cell proliferation. Cell 117: 211-223, 2004.

19. Galili N, Davis RJ, Fredericks WJ, et al: Fusion of a fork head domain gene to PAX3 in the solid tumour alveolar rhabdomyosarcoma. Nat Genet 5: 230-235, 1993.

20. Parry P, Wei Y and Evans G: Cloning and characterization of the $\mathrm{t}(\mathrm{X} ; 11)$ breakpoint from a leukemic cell line identify a new member of the forkhead gene family. Genes Chromosomes Cancer 11: 79-84, 1994.

21. Tuteja $\mathrm{G}$ and Kaestner KH: Forkhead transcription factors II. Cell 131: 192, 2007.

22. Lam EW, Francis RE and Petkovic M: FOXO transcription factors: key regulators of cell fate. Biochem Soc Trans 34: 722-726, 2006.

23. Burgering BM and Kops GJ: Cell cycle and death control: long live Forkheads. Trends Biochem Sci 27: 352-360, 2002.

24. Zhang X, Tang N, Hadden TJ and Rishi AK: Akt, FoxO and regulation of apoptosis. Biochim Biophys Acta 1813: 1978-1986, 2011.

25. Accili D and Arden KC: FoxOs at the crossroads of cellular metabolism, differentiation, and transformation. Cell 117: 421-426, 2004.

26. Datta SR, Dudek H, Tao X, et al: Akt phosphorylation of BAD couples survival signals to the cell-intrinsic death machinery. Cell 91: 231-241, 1997.

27. Li P, Lee H, Guo S, Unterman TG, Jenster G and Bai W: AKT-independent protection of prostate cancer cells from apoptosis mediated through complex formation between the androgen receptor and FKHR. Mol Cell Biol 23: 104-118, 2003.

28. Leger DY, Liagre B and Beneytout JL: Role of MAPKs and NF-kappaB in diosgenin-induced megakaryocytic differentiation and subsequent apoptosis in HEL cells. Int J Oncol 28: 201-207, 2006.

29. Bost F, Aouadi M, Caron L and Binetruy B: The role of MAPKs in adipocyte differentiation and obesity. Biochimie 87: 51-56, 2005.

30. Chang F, Steelman LS, Lee JT, et al: Signal transduction mediated by the Ras/Raf/MEK/ERK pathway from cytokine receptors to transcription factors: potential targeting for therapeutic intervention. Leukemia 17: 1263-1293, 2003. 